\title{
The concept of innovative receptivity: methodological aspects
}

\author{
Vladimir Antropov, ${ }^{1}$ and Natalia Neklyudova ${ }^{1 *}$ \\ ${ }^{1}$ Institute of Economics, Russian Academy of Science (Ural Branch), Moskovskaya, 29, Ekaterinburg, \\ Russia
}

\begin{abstract}
The development of emerging economies determines the need to include innovation activities as the main factor at all levels of government. However, in practice, there is a disparity between the availability of innovative opportunities and their real implementation. It is caused by the lack of comprehensive research and conceptual approaches to the mechanisms for innovative potential formation and development. The purpose of the paper is to identify and describe the features that form the structure of 'innovative receptivity' concept in the economy. The study used methods of component, comparative and contextual analysis. As a result of the research, the definition of 'innovative receptivity' is given. It is an economic concept that characterizes the ability of an organization and a person to perceive innovations, the ability to create and apply pioneering technological innovations, and the willingness of an organization to implement and reproduce an innovation for the first time. This definition characterizes the essential features of the concept.
\end{abstract}

\section{Introduction}

The necessity for accelerated development of Russia, stated in a number of government documents, determines the need to include active innovation activities at all levels of government as the main factor for the successful implementation of acceleration. The Strategy "Innovative Russia-2020" specifies five key tasks that are necessary for solving them [1].

The first task is to change people, increase their sensitivity to innovation, expand the class of innovative entrepreneurs, and create an atmosphere of risk tolerance. An innovative economy needs an innovative person, someone who is focused on creating and implementing innovations in all areas of public life.

On this way, first of all, it is necessary to specify the conceptual and categorical apparatus of research, to clarify the essential features of the concept of "innovative receptivity" and its accompanying concepts in the system of generic relations: innovation, potential, innovative potential, labor potential, innovative activity and receptivity. Having obtained the desired concept in its essential features, it is possible to solve the most important task of forming a holistic mechanism for the development of innovative receptivity at all levels of the

* Corresponding author: nnp81@email.ru 
organization (industry, enterprise, educational institutions, the personality of a particular employee) on the basis of the developed methodology.

\section{Methodology}

The study used methods of component, comparative and contextual analysis. First of all, it is necessary to clarify the essential features of the concept of "innovative receptivity" and its accompanying generic relations in the system. These include innovation, potential, innovation potential, labor potential, innovation activity, and receptivity.

Using a deductive approach, we will start with the concepts of a higher level (categories), and this is potential, and finish with the most specific, professionally significant for us innovative receptivity. For more concreteness, this is the employee's receptivity to innovation in relation to his/her workplace.

Without pretending to complete the discussion, we will express our point of view on the leading concepts of this problem in their essential features, in order to operate with them understanding the meaning of the definitions.

The Austrian economist J. Schumpeter introduced the term "innovation" in his paper Theory of Economic Development and for the first time considered the issues of new combinations of changes in development (i.e., the issues of innovation), giving a complete description of the innovation process [2].

A broader interpretation of this term is given by the Oxford Explanatory Dictionary [3], as well as by the recommendations of the international standards "Oslo Manual" [4].

The concept of "innovation" is also introduced by a number of Russian government documents, including federal laws where innovation is understood as a new or significantly improved product, service or process introduced into use, a new sales method or a new organizational method of business practice, in the organization of workplaces or in external practice [5].

It can be stated that the concept of "innovation" is quite fully disclosed both at the theoretical and methodological and practical levels.

The next concept is «potential». As the literature sources show, the study of the organization's potential and its susceptibility to innovation is an independent urgent task [6].

For the purpose of our study, it is important to combine these concepts ("potential" and "innovation"). It forms a new definition - "innovative potential".

The interpretation of the term «innovative potential» is different. We can say that this is a kind of characteristic of the system's predisposition to change, progress, i.e., its ability to do the following:

- to percept new professionally relevant information;

- to increase the professional knowledge of the labor collective (the growth of professional competencies);

- to put forward new competitive ideas (formulation of actual predictive hypotheses).

The concept of «innovative potential» is widely used in many human sciences. In relation to our research problem, it is important to consider the concept of labour potential as a carrier (accumulator) of innovative potential.

In literary sources, the labour potential of an individual, an enterprise, a territory, and a society are distinguished [7]. It consists of many components, the main of which are health, education, professionalism, motivation, ability to work in a team, the level of creative activity, organization, etc.

The key concept of our research is «innovative receptivity of the organization's labour potential». When starting to discuss this complex concept, it is necessary to keep in mind the existing inconsistency of the conceptual and terminological apparatus [8].

In the classical approach, innovative receptivity (innovativeness) is the ability to create 
and apply pioneering technological innovations, or the willingness and ability of an enterprise (organization) to implement for the first time and reproduce (perceive) the innovation [9].

The analysis of the literature shows that researchers perceive this concept on three levels:

- the susceptibility of socio-economic systems [10];

- the receptivity of the labor potential of the organization as a whole [11];

- the receptivity of the individual (the cognizing subject) to innovation [12].

As part of our research, we will first turn to the innovative receptivity of the individual, the citizen. The employee will be receptive to innovations - the labour collective will also be receptive to innovations if the appropriate motivational environment is laid down in the organization in relation to it.

The analysis of the interpretations of the concept of "innovative receptivity" as an object of scientific research allows us to identify the following methodological characteristics:

- this is a complex indicator;

- this is an economic concept,

- receptivity is considered in relation to a specific area: in our case, in relation to the ability of an organization and a person to perceive innovations;

- receptivity can be realized in innovations in various industries (industry, services, science, etc.).

Innovation receptivity involves the process of evaluating an innovation, initiating its adoption, implementing the innovation, and making it routine.

The list of available publications does not sufficiently include works related to the methodology and methods of increasing the innovation sensitivity of various subjects of Russian society [13].

This is due to the lack of consensus on the essence of the concept of "innovative receptivity". Voyteshonok and Paramonova also support this opinion [12]. Therefore, according to some authors there is no clear and unambiguous conceptual framework for the definition of innovative receptivity. The authors propose to consider the notion in relation to innovation activity and innovation potential.

According to Vasilyev formation of innovative receptivity of the labour potential in Russia as an important part of modern economic thinking [14]. We agree that only the formation of the innovative receptivity of Russian citizens, will lead Russia to the path of accelerated dynamic development and leading positions in the world.

One more example of the fact that there is no common understanding of "innovation receptivity" among researchers is the paper by Teterinets [15]. The author argues that the innovative receptivity of the employed is low in a number of sectors of the national economy. Under the innovative receptivity he understood the number of people with higher education. Further, the author states that "the main indicator of the level of innovation receptivity of the personnel of the Belarusian agro-industrial complex may be the proportion of the number of researchers with academic degrees" [15]. Thus, the question of determining innovation receptivity, on the one hand, is excessively narrowed (only people with academic degrees are innovative in the author's interpretation), and on the other hand, remains open for detailed discussion.

It can be said that this concept is gradually entering the everyday life of modern economic thought, having an interdisciplinary character. It can be attributed to natural science disciplines, where it is quite well known. An interdisciplinary sociological approach can be traced in the work of sociologists, where innovation sensitivity is considered as "the ability and willingness of managers and of organization staff to create, master and implement innovations"[16]. We agree with the position, innovation sensitivity means the ability and readiness of the staff to acquire new knowledge, but the values and attitudes, from our point of view, are the initially set parameters of the organization, its internal factors. As well as the 
willingness to implement innovations is not an innovative receptivity, but the formulation of the algorithm to achieve the goal, this is a certain action.

The concept of innovative receptivity can also be considered as psychological one. Innovative receptivity is primarily the receptivity of innovations, ideas, and novelty. From these positions, a number of authors promote the idea of a mechanism for introducing and distributing innovations in the form of memes that act on the psychological level. The concept of memes was first introduced by Richard Dawkins in 1976 in his book The Selfish Gene [17]. Further, the supporters of this idea develop the method for creating and launching such memes.

Of course, there is a difference between the concepts of "perception" and " receptivity»: "perception" can be considered as a process of cognition, and "receptivity" - as a certain property of the cognizing subject. This is how this concept is perceived when it comes to the receptivity of the organization's labor potential to innovation.

In relation to regional socio-economic systems, their innovation sensitivity is understood as the ability of such a system to incorporate changes caused by the innovation process into its structure and activities. Persky and Zavyalov consider the innovation process as a set of actions to create innovations [10].

\section{Results and discussion}

The above-mentioned and other literature sources indicate that today, in the age of innovation, there is practically no well-established definition of the term "innovative receptivity". It is being formed only at the level of imagination, i.e. on the basis of intuitive interpretation, without highlighting its essential features and formulating definitions. However, the accumulated amount of knowledge allows us to formulate this concept and show its place in the system of subsumption relation.

First of all, "receptivity" is a property of purposeful perception of information (knowledge) that is significant for a person, the comprehension and transformation of which ensures the achievement of the goal set by the subject along the optimal trajectory. In this process, the main thing is the selection of the necessary information. In modern conditions, it is optimized by developing information technologies (IT).

Other characteristics of "innovation receptivity" can include the following (in addition to those discussed above):

- the ability to identify and evaluate "its own" innovation that fits into the trend of the organization's development;

- $\quad$ ability to perceive innovations (readiness to perceive);

- responsiveness to innovations (availability of the necessary time lag);

- responding not only to innovation, but also to novelties;

- the ability to implement innovation (the presence of an appropriate level of labor potential development, modern equipment and technologies);

- the necessity and economic feasibility of production diversification for innovation;

- the readiness of the labor potential of the team to accept the proposed innovation (the level of resistance to change);

- the ability of the organization's management to overcome resistance to change.

Many articles consider the innovative receptivity of an organization's labour. Rudaleva and Kabasheva analyse the innovative receptivity of employees and the factors influencing it [18]. For the analysis, they use the example of road construction organizations. In their opinion, the level of innovation sensitivity, as part of the innovation potential of the organization, reflects the ability to implement innovations. This is possible only if there is an educational potential of the labour, interested in the state of affairs in the organization, through the attitude to the changes that always accompany any innovation, through the 
understanding of the essence and necessity of innovations of a particular type and the role of the employee in their creative performance.

The incentive factor for the formation of an organization's innovation receptivity is the degree of market activity, including innovative products, as well as the activity of competitors and the pressure from the competitive environment as a whole.

Innovation sensitivity is manifested in the ability and willingness of managers and staff of organizations to create, master and implement innovations. It reflects the degree of motivation of managers and staff of organizations to implement permanent innovations.

The basis of the innovative receptivity of the collective (staff) of the organization is its readiness to acquire new knowledge, values, and attitudes.

Its essential quality is innovation activity. There may be a situation where the receptivity of the labor potential may be at a sufficient height, but the activity of employees is not. The solution to this problem is in the personnel motivation system. It can be realized by a dialectical combination of the employee's personal need for development and the company's need to develop, relying on the labor potential of employees.

The innovative activity of the enterprise included in the production process also largely depends on the material and technical characteristics of the organization. For example, if an organization has the necessary resources to innovate, or if it has an effective technical base to innovate, it will certainly be more receptive to innovation.

Another characteristic of the staff is the involvement of employees. The relationship between employee engagement and business performance is scientifically proven. According to the Gallup Institute, global companies annually suffer more than $\$ 300$ billion losses due to the low productivity of their indifferent employees. In contrast, companies with a high level of engagement have $18 \%$ higher productivity and $40 \%$ lower employee turnover [19]. Engagement contributes to better adaptation in the company, improves the quality of employee interaction with customers, with each other, reduces motivation costs, and forms a strong PR brand of the company.

Gusakov revealed that the staff's readiness to implement innovations accounts for $80 \%$ of success, while the lack of correct perception of such results in the complete failure of innovations [20].

Innovative processes designed to ensure the survival of the enterprise in market conditions, as a result, do not always turn out to be painless for the staff and sufficiently effective for them.

The concretization of the concept of innovation receptivity determines the need for the formation of the process of diagnosing and evaluating innovative characteristics.

Diagnostics of innovation receptivity in a systematic form in our understanding can be presented in the form of characteristics of three blocks:

- socio-economic system (region, industry);

- the labor potential of the organization as a whole;

- characteristics of the personality (the cognizing subject) in relation to innovations.

- It is assumed that the assessment (measure) of innovation receptivity should be an integral parameter, as is the concept itself.

In the situation of the real economy, the «innovation receptivity» itself cannot be a constant, since the degree of its development depends on many internal and external environmental factors, and therefore it must be a controlled system with clearly defined mechanisms.

The creation of such a managed system is the way to effectively modernize the regional economic complex and each specific organization.

\section{Conclusion}


The analysis of the literature sources allows us to conclude that there is no single integrated approach to assessing innovation receptivity at all levels of management in modern theory and practice.

When introducing innovations, we should not forget about resisting them. This is a natural dialectical process of "introduction-resistance". To sort out differences, we need a clear conceptual construct.

Summing up the results of understanding the conceptual and categorical apparatus of the study of "innovation receptivity", we can formulate its following definition. Innovation receptivity is an economic concept that characterizes the ability of an organization and a person to perceive innovations, the ability to create and apply pioneering technological innovations, and the willingness of an organization to implement and reproduce an innovation for the first time. This definition characterizes the essential features of the concept; additional features are displayed in the text. All of them are preliminary and will be specified in the course of further research.

\section{References}

1. Order of the Government of the Russian Federation of 08.12.2011 N 2227-p. On the Strategy for Innovative Development of the Russian Federation for the period until 2020, www.consultant.ru/document/cons doc LAW 123444/, [Accessed: 03 April 2021)

2. J. Schumpeter, U. Backhaus, The theory of economic development, In: Backhaus J. (eds) Joseph Alois Schumpeter. The European Heritage in Economics and the Social Sciences, 1, 61-116, Springer, Boston, MA (2003)

3. Business: Oxford Explanatory Dictionary (1995)

4. Oslo Manual: Proposed Guidelines for Collecting and Interpreting Technological Innovation Data (1992)

5. On science and state scientific and technical policy: Federal Law of the Russian Federation as of August 23,1996 No. 127-FZ, http://www.consultant.ru/document/cons_doc_LAW_11507/, [Accessed: 20 June 2021)

6. E. V. Popov, Int. Adv. Econ. Res., 10(4), 337-338 (2004)

7. B. S. Pavlov, Reproduction of human potential in the region: theoretical and methodological aspects of socio-economic analysis (on the example of the Urals), Yekatrinburg: In-t ekonomiki UrO RAN, (2014)

8. O. A. Romanova, T. A. Nelyubina, Economy of Region, 3, 211- 217 (2010)

9. B. Z. Milner, Innovative development: economy, intellectual resources, knowledge management, (M.: INFRA-M, 2010)

10. Y. K. Perskiy, A. Y. Zavialov, ARS Administrandi, 1, 27-36 (2014)

11. G. A.Reznik, D. R. Amirova, Economics and management of innovative technologies, 12 (2014), [Online], https://ekonomika.snauka.ru/2014/12/6616, [Accessed: 09 June 2021]

12. M. Voyteshonok, I. Paramonova, Science and Innovation, 1(143), 29-32 (2015)

13. I. Toropova, A. Mingaleva, P. Knyazev, Assessment of the Factors' Impact on Innovation Activity in Digital Age, In: Antipova T. (eds) Integrated Science in Digital Age 2020, ICIS 2020, Lecture Notes in Networks and Systems, 136, Springer, Cham. (2021) 
14. P. P. Vasiliev, Terra Economicus, 8(1, part 3), 103-109 (2010)

15. T. Teterinets, Science and Innovation, 5(195), 38-44 (2019)

16. S.A. Ilyinykh, E.V. Mikhailova, Theory and Practice of Social Development-Int. Sci. J. Sociol. Econ. Law, 14, 12-14 (2015)

17. R. Dawkins, The Selfish Gene, (Oxford University Press, USA, 1976)

18. I. A. Rudaleva, I. A. Kabasheva, Fundamental Research, 11(part 4), 872-876 (2014)

19. GallupQ12® Meta-Analysis Report, https://www.gallup.com/workplace/321725/gallup-q12-meta-analysis-report.aspx, [Accessed: 20 June 2021]

20. M. A. Gusakov, Econ. and Manag., 8, 33-39 (2016) 